Res Pública Revista de Historia de las Ideas Políticas

ISSN: 1131-558X

https://dx.doi.org/10.5209/rpub.75406

\title{
J. L. Villacañas, Eremitas, andalusies y mozárabes. Las sociedades ibéricas bajo el poder islámico, Madrid, Guillermo Escolar editor, 2018, 351 pp.
}

José Luis Villacañas apenas necesita presentación. Filósofo, historiador de las ideas (y de los hechos, de donde su doble faceta como historiador de la filosofía e historiador simpliciter), filósofo de la política, escritor, poeta y novelista, en la actualidad es catedrático de Historia de la filosofía española en la Universidad Complutense. Su producción bibliográfica es enorme, siempre sin desdoro de la finura analítica y la calidad científica, como se deja ver en este trabajo que presentamos.

Eremitas, andalusíes y mozárabes: las sociedades ibéricas bajo el poder islámico es el segundo volumen de una colección titulada La inteligencia hispana. Ideas en el tiempo, que está proyectado alcance veintiún volúmenes, hasta la España de nuestros días. De esta colección han visto ya la luz tres primeros volúmenes: el primero, El cosmos fallido de los godos (Madrid, 2017, 252 pp.); el tercero, El gran siglo de Abderramán III. Crisis y europeización de los poderes hispanos (9121065) (Madrid 2019, 355 pp.). La aparición sucesiva en solo tres años de libros de tanto fuste nos da una idea de la capacidad y disciplina de trabajo de su autor.

El presente volumen describe e interpreta los hechos acaecidos y las ideas dominantes entre los siglos VIII y $\mathrm{X}$ en la península ibérica, que en esta época, de Hispania romana y Gotia visigótica, pasa a ser al-Ándalus. Si la descripción es en general de hechos conocidos, la interpretación es en muchos casos lúcida y novedosa, como veremos sobre todo a propósito del capítulo quinto.

El libro se compone de introducción, ocho capítulos, índice onomástico, una oportuna relación de reyes (astur-leoneses y francos, tanto merovingios como carolingios) y una bibliografía, dividida entre fuentes y literatura secundaria. El articulado de los capítulos es el siguiente: El comparativo europeo: los francos (cap. $1^{\circ}$ ), Una conmoción histórica (cap. $2^{\circ}$ ), Los hechos (cap. $3^{\circ}$ ), La época de Alfonso II (cap. $4^{\circ}$ ), La lucha por la ortodoxia en los tiempos de Alfonso II (cap. $5^{\circ}$ ), El emirato de Córdoba (cap. $6^{\circ}$ ), La crisis de la sociedad mozárabe (cap. $7^{\circ}$ ) y, finalmente, Alfonso III y la evolución de los núcleos cristianos hasta el inicio del siglo X(cap. $\left.8^{\circ}\right)$.

$$
* * *
$$

Para hacerse una idea algo más detallada del contenido del libro, hacemos una sucinta presentación de los capítulos referidos. El capítulo primero se dedica a la evolución de los francos, desde Clodoveo hasta Carlomagno. De particular relevancia nos parece la afirmación de que "el ascenso de los carolingios es un efecto del islam, que debilitó de manera intensa la capacidad del reino merovingio" (p. 19). Siguiendo la tesis de H. Pirenne (cf. Mahoma y Carlomagno, Alianza, Madrid 1978) Villacañas sostiene que "Carlomagno es un efecto de Mahoma", siendo el único "que tradujo en éxito el fracaso general del mundo cristiano frente a la irrupción islámica" (p. 23). Reseñable, asimismo, es el estudio de Villacañas de la idea de realeza expuesta por Jonás de Orleans en su De institutione regia (828), en donde se presenta el sentido de la idea imperial carolingia, cuyo eco llega a los caudillos hispanos del norte que tratan de imitarla. La aspiración central de esta obra es definir la relación entre poder real y poder sacerdotal (cf. p. 71).

El segundo capítulo aborda las fuentes de que disponemos para hacer una historia de los primeros tiempos tras la conquista musulmana de Hispania. En él se muestra "la asimetría entre las fuentes contemporáneas hispanas que dieron cuenta de la derrota de Rodrigo y la inexistencia de relatos tempranos escritos en árabe acerca de la conquista de al-Ándalus" (p. 19). Mientras las primeras crónicas islámicas de la conquista, que se inspiran en las crónicas imperiales bizantinas, son pocas, de fecha tardía y escritas fuera de Hispania (en efecto, datan de Egipto no antes del 850), las crónicas cristianas son abundantes y las primeras son muy próximas a los hechos de la invasión. En concreto, las primeras, de mediados del siglo VIII, son la Crónica de 741, también llamada Continuatio Bizantia Arabica, y la Crónica de 754 o Continuatio Hispana. Entre ellas hay algunas diferencias notables, como son la diferente valoración del islam, más positiva en la primera. También es interesante que solo la Crónica de 741 distingue claramente a los árabes y bereberes como los dos grandes grupos musulmanes de la conquista. Un segundo grupo de escritos, ya de finales del siglo VIII, fundamentales para el conocimiento de la figura de Alfonso II, son ciertos elementos cronísticos o pasajes (que luego aparecerán insertos en el gran ciclo de Alfonso II (791-843) con el nombre de Crónica Profética), junto con la obra de Beato de Liébana. Finalmente, un tercer ciclo cronístico, de finales del siglo IX y principios del $\mathrm{X}$, corresponden a la época de Alfonso III (866-910), compuesto por la Crónica albeldense (Oviedo, 881) y las dos versiones de la Crónica de Alfonso III (la Rotense y la ad Sebastianum), que se inspiran y pretenden continuar la Historia gothorum de san Isidoro. En estas últimas crónicas ya se conoce la radicalización de la resistencia cristiana en la Bética, el aumento de la emigración mozárabe al norte, los mártires de Córdoba y considera, ahora así, insoportable la 
dominación musulmana. La nota más relevante de este tercer ciclo cronístico es la voluntad de establecer una "continuidad de Asturias-León con la tradición gótica" (cf. p. 93).

Después de estudiar las fuentes, el capítulo tercero hace lo propio con los hechos, sea desde el punto de vista militar sea social. Los hechos, en lo fundamental, son una invasión sin grandes campañas guerreras y frecuentes pactos de sumisión, acompañados a veces de la conversión al nuevo monoteísmo. El pacto de sumisión se rompió tanto por los hispano-godos (de lo que tenemos constancia por el primer núcleo de resistencia de Pelayo en las montañas asturianas), como también por buena parte de los contingentes bereberes que acompañaban a los conquistadores. Al sur de las montañas norteñas, de otro lado, se fue conformando el pueblo andalusí. Debido a la pujanza de la nueva monarquía franca, los núcleos cristianos de la montaña supieron resistir en una época en que en el sur se empezaba a estabilizar el poder en manos del primer emir independiente de al-Ándalus, Abd al-Rahman I (731-788).

El capítulo cuarto aborda la evolución del núcleo cristiano con Alfonso II. Después de Abd al-Rahman I los musulmanes abandonaron las montañas gallegas, asturianas, cantábricas, vacas y pirenaicas. "Los árabes llegan hasta donde alcanzan los llanos", había sentenciado Ibn Jaldún, un historiador de origen andalusí. Abd al-Rahman I puso su empeño en asegurar la primacía del poder de Córdoba. Los omeyas cordobeses no necesitaban asegurar los pasos montañosos, toda vez que habían renunciado a conquistar el territorio de la vieja Hispania, Pirineos y Galia gótica incluidos (cf. p. 153). Abd al-Rahman I se volcó en un programa de gobierno que no hacía sino "restaurar en la más lejana provincia de la periferia del Islam, las formas que la dinastía omeya ejerció en Damasco, bastante relacionada con las formas bizantinas" (p. 154). El renovado poder franco aseguraba a los territorios cristianos del norte hispánico su subsistencia. Era el reino franco una última línea de protección, no un poder en que los hispanos norteños desearan integrarse. Aunque cristianos, los francos eran ya otra nación. Las leyendas en torno a la epopeya de Roldán lo muestran claramente. Solo con Alfonso II, a finales del siglo VIII, puede decirse que nace el reino asturiano, sostiene Villacañas. Antes de él existen unas dinastías de caudillos cristianos confederados. También con él aparece la imitación de las formas de poder y el sentido de la realeza francas, aunque solo Alfonso III se llamará a sí mismo rex.

En el capítulo quinto, como veremos con algo más de detalle después, se estudia el sentido del cristianismo que se generó en Asturias en contraposición con la sede crecientemente mozárabe de Toledo. Asistiremos aquí a las disputas sobre el adopcionismo y al sentido del apocalipticismo que, a través de los Comentarios de Beato, llegó a ser uno de los factores comunes de la cultura hispana y cristiana de la época (cf. p. 20), así como al surgimiento de la figura de Santiago.

El capítulo sexto aborda la construcción política que organizó Abd-al-Rahman II en al-Ándalus y el sentido de la nueva realeza andalusí, a la vez que el estudio de la incorporación del islam andalusí al movimiento malikita, caracterizado por una mayor intransigencia teológica, con la mímesis de realidades orientales y la transformación del ideario omeya originario (que no daba a Mahoma la importancia que los abásidas de Bagdad le atribuían) en favor de una comprensión más general de la comunidad islámica (cf. p. 20).

El capítulo séptimo se consagra a la evolución del cristianismo mozárabe bajo las nuevas condiciones impuestas por la ideología malikita, ya claramente vencedora en el emirato de Abd-al-Rahman II, y con plena capacidad para moderar la teología del Dios transcendente y equilibrarla con el papel del Enviado, es decir Mahoma. "Con ello avistaremos la tensión que conoció la comunidad cristiana mozárabe y el intento de transferir al sur el viejo sentido apocalíptico del norte astur, definido medio siglo antes por Beato" (p. 21).

Finalmente, el capítulo octavo estudia el reino de Alfonso III y sus logros, su capacidad de mantener la expansión del núcleo astur-leonés y la configuración de una nueva ideología goticista, que se transferirá desde comienzos del siglo X al reino de León (cf. p. 21).

$$
* * *
$$

El libro se abre con estas palabras: "En el año 711 se puso fin a la dominación política goda sobre la tierra hispana y una nueva minoría dirigente, dotada de una cultura todavía en formación, pero ya expansiva e integradora, y de una fuerza militar impactante, asentada con firmeza sobre estímulos religiosos monoteístas, asumió la visibilidad del poder supremo sobre las tierras peninsulares" (p. 7). Acerca de la invasión musulmana, Villacañas afirma que "como hoy se defiende con vigor, se trató primero de una ocupación militar y fiscal, y luego ya con los omeyas de una penetración religiosa, cultural y administrativa" (pp. 8-9), aunque, en todo caso, "la invasión fue consecuencia de una radical decadencia de la dominación goda", como demuestra el hecho de que, frente a "los partidarios de Rodrigo, sus oficiales y soldados, que plantaron resistencia en algunos sitios", la indiferencia fue general en la población y abundantes fueron las deserciones de los nobles. De este modo, aunque hubo focos de resistencia, la nota dominante fue la inclinación al pacto, acompañada de una generalizada indiferencia, pues "para la inmensa mayoría de la gente, una nueva minoría con poder militar venía a sustituir a los godos, por cierto una casta no especialmente prestigiosa" (p. 9). La evolución hacia el pacifismo de la sociedad goda debilitó la capacidad combativa del poder hispano. De otro lado, tras la muerte de Rodrigo nadie disponía de un poder unificado capaz de resistir a una caballería eficaz como era la sarracena. Pero incluso una caballería organizada como la de Musa no podía operar sobre el terreno sino mediante pactos (cf. p. 15).

Con todo, hay una causa de especial peso en la conquista de Hispania, como es la reordenación de las relaciones de poder en Oriente. "Hispania ya no tenía ni en Toledo ni en Bizancio su razón política ni su legitimidad. Lo que sucedía en ella reflejaba ese cosmos oriental expandido que desplegaba sus ondas desde Damasco" 
(p. 93). La lenta genealogía del Islam no se comprende sin el retroceso de Bizancio y de la Persia sasánida. Tras la victoria bizantina en la batalla de Nínive del 627 y el asesinato del emperador persa Cosroes en 628, el imperio persa quedó resquebrajado, pero también Bizancio se replegó. "Entonces todos los pueblos que antes habían guerreado a favor de unos y otros, descubrieron que en el hueco dejado en el repliegue de los dos grandes poderes, había espacio para su propia expansión" (p. 88). Los pueblos orientales aludidos eran caldeos, sarracenos, árabes, agarenos o ismaelitas (también llamados a veces hijos de Abraham), judíos, mauri, bereberes, etc. Todas estas poblaciones se habían mantenido en estrecha relación con bizantinos y persas. Característica central de estos pueblos era un monoteísmo alternativo "a los pluralismos, el trinitario [de Bizancio] y el dualista [de Persia]" (p. 86). Sin embargo, en este conglomerado de pueblos de base monoteísta destacaban aquellos que tenían una base lingüística árabe, lo que ofreció una condición étnica dominante a la futura cristalización islámica. Así, "se configuró en esta zona de frontera un monoteísmo de base lingüística árabe, algo que iba a resultar decisivo para el islam como religión" (p. 86). Se entiende así por qué en las crónicas de Sofronio (560-638), patriarca de Jerusalén, y de Juan Nikiu, obispo copto en Egipto en 694, se habla de la fragilidad y reocupación del espacio sasánida protagonizada por pueblos de diversas denominaciones, pero sin hacer mención de un poder islámico nítido. De este modo, en el intersticio entre estos dos imperios, "unos pueblos hasta ahora subalternos poco a poco percibieron la debilidad que había producido el viejo enfrentamiento [entre Bizancio y Persia] y se expandieron reocupando los espacios que los imperios dejaban en su repliegue" (p. 90). De otro lado, la constatación de la impotencia bizantina cambió los hábitos de los sarracenos, disminuyendo su antiguo nomadismo, invitándoles al asentamiento en los lugares en que entraban. Las correrías dieron paso así a los asentamientos. Esta misma conciencia alteró igualmente la percepción sobre Hispania en su conjunto y el nuevo hábito determinó su irreversible entrada en el 711.

Villacañas lleva a cabo así una oportuna y clarificadora ampliación del campo visual sobre los hechos de la conquista. Lo que sucede en el Oriente medio del siglo VII permite comprender mejor los hechos que tuvieron lugar en el 711 en la península ibérica, que no fueron sino "la última ola expansiva de la reocupación de todos los espacios abandonados por el imperio bizantino" ( $p$. 91). La imagen del 711 se enriquece así enormemente, a la vez que se hace más contextualizada. Se corrige también así la idea, verdadera pero parcial, de un proceso meramente endógeno de autodestrucción goda. Las sucesivas oleadas de africanización, orientalización y arabización fueron posibles porque "las rutas estaban expeditas en un Mediterráneo interconectado y sin poder cristiano hegemónico" (p. 91).

Tras la invasión los dominados pactaron en muchos sitios con los nuevos señores, "y como la religión de estos era más simple, llevadera y concreta, y su régimen fiscal al principio más benévolo, al no imponer de entrada la doble tributación religiosa y pública, muchas poblaciones se entregaron a la nueva mentalidad" (p. 9). Villacañas sostiene que "no podemos asumir que toda la población hispana mantuviera un cristianismo maduro y regulado", antes bien se debe suponer que "muchas gentes rurales se entregaran por primera vez a una gran religión monoteísta cuando abrazaron el Islam" (p. 9). Sabemos, en efecto, por san Martín de Braga en su De correctione rusticorum hasta qué punto eran frecuentes entre los rústicos (es decir, entre las gentes del rus, los campesinos) las reliquias de un paganismo ancestral, acompañado de las prácticas y supersticiones precristianas (fueran romanas, fueran germánicas, en este caso suevas) en aquella parte de Hispania catequizada por él, la Gallaecia. Con este opúsculo san Martín de Braga no hacía sino proseguir las huellas del De catechizandis rudibus de san Agustín. En cualquier caso, rustici y pagani (del pagus) eran los habitantes de los campos, donde la fe cristiana, expandida preferentemente en las ciudades romanas, no había arraigado aún con profundidad.

Las sociedades andalusí y cristiana (replegada esta hacia el norte montañoso) comenzaren entonces a relacionarse entonces como dos sociedades complejas y en devenir, en una dialéctica de influencias, imitaciones y enfrentamiento. Sin embargo, el eco de los grandes poderes del tiempo (los francos y los califatos de Damasco y de Bagdad) se hace sentir en esta tierra de frontera entre los grandes poderes del momento. Villacañas lo describe con nitidez: "No entenderemos el ritmo, el estilo, el respirar de esta dialéctica de sociedades si miramos solo esa línea de fricción de la frontera cristiana y andalusí. De forma a veces intensa y a veces diluida, en esa línea de fricción siempre se hacen presentes realidades lejanas, que proceden de los grandes poderes que enmarcan estos dispares órdenes de frontera. Más allá de los Pirineos, la evolución de los francos, tan diferente de la evolución de los godos, va a ser decisiva no solo para detener a los jinetes sarracenos, sino para reorganizar los territorios norteños peninsulares de manera que puedan resistir a la ofensiva sarracena [...] De la misma manera, la destrucción del califato de Damasco y la fundación de Bagdad, con las nuevas formas de comprensión del Islam y la evolución de los poderes en el norte de África, afectarán de forma decisiva la construcción de la sociedad andalusí" (p. 18).

$$
* * *
$$

El capítulo quinto es, por diversas razones, el que más interesa a quien escribe estas líneas. En él se abordan cuestiones teológicas, pero cargadas de sentido político. Titulado La luchas por la ortodoxia en los tiempos de Alfonso II, este capítulo dedica sus epígrafes segundo, tercero y cuarto al estudio del adopcionismo, de Santiago y del apocalipsis de Beato de Liébana, respectivamente.

En el epígrafe segundo presenta Villacañas una brillante exposición del contexto del adopcionismo, raramente estudiado por los teólogos. El adopcionismo, sostenido por los obispos Elipando de Toledo y Félix de Urgel y combatido por los monjes Beato de Liébana y Alcuino de York, era una suerte de renovación tardía 
del nestorianismo (condenado en Éfeso). Sostenían los adopcionistas que Jesucristo es en su humanidad hijo adoptivo, no natural, del Padre. Ahora, como la filiación se dice de la persona, no de la naturaleza, en Cristo habría dos personas, la humana y la divina. Esta doctrina fue denunciada por Beato en el Apologeticum adversus Elipandum: "Una pars episcoporum [Elipando, en efecto] dicit quod Jesus Christus adoptivus est humanitate et nequaquam adoptivus divinitate. Altera pars dicit: nisi ex utraque natura unius est Dei Patris filius proprius, ut ipse sit Dei filius, Deus verus [...]. Haec pars nos sumus, id est, Etherius et Beatus cum caeteris ita credentibus" (lib. I). El adopcionismo hispano fue condenado en el concilio de Frankfurt de 794, convocado por Carlomagno, junto con la herejía iconoclasta. En dicho concilio provincial decía la Epistola synodalis episcoporum Franciae ad praesules Hispaniae, titulada De Christo Filio Dei naturali, non adoptivo: "Invenimus enim in libelli vestri principio scriptum, quod posuistis vos: «Confitemur et credimus Deum Dei Filium ante omnia tempora sine initio ex Patre genitum, coaeternum et consubstantialem, non adoptione, sed genere». Item post pauca eodem loco legebatur: "Confitemur et credimus eum factum ex muliere, factum sub lege (cf. Gal 4.4), non genere esse Filium Dei, sed adoptione, non natura, sed gratia». Ecce serpens inter pomifera paradisi latitans ligna, ut incautos quosque decipiat [...]" (DenzingerSchönmetzer, Enchiridion symbolorum definitionum et declarationum, Barcelona, Herder, 1967, pp. 205-206). Que el interés por la cuestión adopcionista pervivía aún a fines del siglo XVI lo demuestran obras como la Historia de rebus Hispaniae (lib. VII, cap. 8: "Elipandus toletanus praesul"), de Juan de Mariana; el libro del jesuita Gabriel Vázquez, Disputationes duae contra contra errores Felicis et Elipandi, de servitute et adoptione Christi in concilio francofurdiensi damnatos (Alcalá de Henares, 1594) y la carta del jesuita Juan Eusebio Nieremberg a Ramírez de Prado, "en excusa de Elipando", dice Menéndez Pelayo (Historia de los heterodoxos españoles, I, Madrid, BAC, 1986, p. 338).

Ahora, como muy bien hace notar Villacañas, en el adopcionismo concurrían elementos de naturaleza extrateológica, como tantas veces ha ocurrido en la historia de las herejías cristianas. En efecto, “el adopcionismo era un intento de captar la benevolencia del invasor musulmán, mostrando los puntos de convergencia entre el islam y el mensaje cristiano" (p. 198). Desconociendo la divinidad del hombre Cristo, al considerarlo como filius adoptivus, se hacía más aceptable la fe a los que aún alimentaban las antiguas creencias arrianas entre los godos mozárabes. Rebajando asimismo a Cristo a la condición de hombre perfecto, pero no Dios, se hacía la fe cristiana aceptable tanto para el islam como para los judíos. Finalmente, así también las cosas eran más fáciles para los cristianos nestorianos presentes en las huestes militares sirias presentes en al-Ándalus. Villacañas alude a un cierto miles referido por Menéndez Pelayo que habría enviado a Elipando un cuaderno de observaciones contra Beato. Ahora bien, "en Toledo, un miles, no podía ser sino un sirio" (p. 187), probablemente un soldado cristiano nestoriano con formación teológica. En cual- quier caso, "allí donde se daba una ciudad fuerte, los contingentes invasores tenían que pactar con sus habitantes [...]. Era lógico que estos cristianos de las ciudades, con su obispo al frente, buscaran formas culturales de aproximación al poder musulmán". De otro lado, "la corte astur, de nuevo en contacto con Aquisgrán, y con el fuerte trinitarismo franco-romano, no podía aceptar el protagonismo ni la dirección espiritual de la metrópolis toledana, que había quedado en manos de aquellas élites que impulsaron los pactos entre los musulmanes, los judíos y los grupos cristianos mozárabes" (p. 184). Es segura la "estrecha alianza [de Beato] con las élites culturales francas, con Alcuino de York al frente", alianza pactada con la plena conciencia de que "el mayor obstáculo para mantener las expectativas escatológicas [como era la lucha contra el anticristo, es decir, el Islam] es Toledo, la capital traidora, la que se ha rendido y pactado con el islam" (p. 183). Tal alianza franco-asturiana tenía el propósito de reivindicar de un lado la pureza dogmática de la fe cristiana (como Beato hace con el Apologeticum) y, del otro, la pureza de las costumbres y la expectativa apocalíptica, tan activa en aquella segunda mitad del siglo VIII (como se puede ver en el Commentarium in Apocalypsin, de nuevo de Beato).

En este contexto de ocupación musulmana y de intensa disputa del norte astur, con fuerte apoyo franco, contra el sur mozárabe hay que insertar el surgimiento de la figura de Santiago. García Villoslada ya lo hacía ver así, al hablar de "la invención del sepulcro de Santiago", en su Historia de la Iglesia católica, II, BAC, Madrid 1988, pp. 414-416. Al respecto, también puede consultarse a J. L. Abellán, Historia crítica del pensamiento español, I, Madrid, Espasa-Calpe, 1988, pp. 240246. Según Villacañas, "en realidad, lo político e institucional era el argumento central de esta polémica [...] Lo decisivo es que tras Beato ya no se podía reconocer la primacía doctrinal y eclesial de Toledo. Así, no solo comenzó a surgir la corte de Oviedo [...] Surge también la sede de Santiago, que sustituiría a Braga, como centro de la influencia franca. A Beato, en caso de que represente a un único monje, debemos el himno en honor del santo, O Dei verbum [784] donde se le llama con todas las letras caput refulgens aureum Ispaniae / tutorque nobis et patronus vernulus [cabeza aurea refulgente de Hispania / defensor nuestro y patrono nativo]. Sin embargo, el himno por sí mismo no era eficaz sin una sede episcopal en la que pudiera lucir la cabeza protectora de España. Fundada la iglesia por Alfonso II, dotada por Alfonso III, la sede de Santiago cristalizó como una segunda Toledo, llamada a ser la iglesia apostólica de Hispania" (pp. 191-192). Frente a la primacía política de Toledo en la iglesia española, Santiago presentaba ahora una legitimidad apostólica, derivada de ser la iglesia fundada sobre los restos del "hermano del Señor". Con ello "el culto a Santiago se separaba de la liturgia toledana e iniciaba su andadura, prestando el elemento más importante a la ideología religiosa del reino asturleonés, con claras influencias francas" (p. 192). Solo entonces, ya después de los tiempos de Alfonso III, "se podrá construir el imaginario de la victoria de Ordoño I en la batalla de Clavijo (859) sobre Musa II de Tudela” 
(pp. 192-193). Como advierte Villacañas, "un complejo nudo de intereses políticos se dio cita en este nuevo culto" (p. 193). La creación del obispado de Oviedo en el 811, "sicut in Toleto fuerat", manifiesta una explícita voluntad de reemplazar a la capital mozárabe. De otro lado, Sánchez Albornoz, como nos recuerda Villacañas, da por segura la reunión de algún concilio en Oviedo, con presencia de los obispos de Iria, Lugo, Valpuesta, etc. Si así hubiera ocurrido, bien podría haber sido convocado este concilio de Oviedo por Carlomagno, cuya intensa actividad político-eclesiástica nos es conocida. Fue él, en efecto, quien, cual nuevo Constantino, convocó los concilios de Ratisbona (792), Frankfurt (794), Friuli (796), etc.

Ortodoxia cristológica contra el sincretismo toledano y expectación escatológica ante la considerada inminente consumación del tiempo: he aquí los dos ejes de la obra de Beato. El capítulo quinto del libro de Villacañas se cierra con un último epígrafe titulado Apocalipsis. Beato es autor de un Commentarium in Apocalypsin. El mismo pathos de san Jerónimo y de san Agustín ante el hundimiento del imperio romano renace en este monje de Liébana, expectante ante la venida de Cristo glorioso. Pero antes del final del mundo, el anticristo perseguirá a los cristianos, como tiempo atrás lo hicieron los emperadores romanos. La nueva persecución se acompañará, según Beato, de dos signos: muchos cristianos colaborarán con los poderes que persiguen a la Iglesia, como ocurría "en el odiado Toledo" (p. 196), y la persecución se hará bajo el signo de la sinagoga. Los cristianos acomodados a las nuevas circunstancias son "falsos sacerdotes que, apoyados en la amistad regia, oprimen a la iglesia y prometen al pueblo seguridad" (Commentarium in Apo- calypsin, 191). He ahí los obispos mozárabes, que han pactado con el anticristo (el poder musulmán), a cambio de asegurar a los cristianos sus propiedades. El anticristo, según Beato, es el que une y confunde en un inconfesable sincretismo iglesia y sinagoga. Es interesante que a los ojos de Beato el islam no es aún una religión específica. "Para él es puro monoteísmo, judaísmo", de manera que "la mezquita es la sinagoga" (p. 199). Lo propio del Anticristo es favorecer "la síntesis de cristianismo y judaísmo". He ahí la renovación de Babilonia, la temida confusión (cf. Commentarium in apocalypsin, 197), la cohabitación de infieles y cristianos en las mismas ciudades de al-Ándalus. El libro de Beato "sirve así de manera espléndida a la propaganda del núcleo cristiano de Alfonso II, que incita a la emigración, a la reunión de los cristianos, a la confederación de pueblos bajo la dirección de un jefe [Alfonso II] cuya única señal es ser el protector de la Iglesia” (p. 202). Nada todavía de reconquista. Nada de avance territorial contra los infieles. Solo salida de Babel y reagrupación cristiana al modo monástico, formando una comunidad en la que los miembros, "los hermanos viven con una sola alma y un solo corazón, a la manera de los Apóstoles" (Commentarium in apocalypsin, 197). He aquí una descripción de "la pulsión de tantos hispani, que abandonando las ciudades mozárabes, se asoman al norte y se integran en los monasterios", pero también un "acto de propaganda [... con el que] Beato es el testigo más preclaro de las comunidades cristianas que se van formando antes de su organización política" en el desierto dejado por los musulmanes entre el Duero y el mar (p. 200).

Leopoldo José Prieto López 